\title{
Morphological Diversity of Mitochondria in Cultured Astrocyte, HeLa, COS7 Cells under High Voltage Electron Microscopy
}

\author{
Hyun-Wook Kim, Seung Nam Park, Younghye Moon ${ }^{1}$, Seung Hak Oh, Im Joo Rhyu* \\ Department of Anatomy, College of Medicine, Korea University, Seoul 136-705, Korea \\ ${ }^{1}$ School of Biological Sciences, College of Natural Sciences, Seoul National University, Seoul 151-742, Korea
}

*Correspondence to:
Rhyu IJ,
Tel: +82-2-920-6149
Fax: +82-2-929-5696
E-mail: irhyu@korea.ac.kr
Received September 24, 2013
Revised September 26, 2013
Accepted September 26, 2013

\begin{abstract}
Mitochondrion is an important intracellular organelle controlling energy production essential for cell survival. In addition, it is closely related to cellular apoptosis and necrosis. Linear, branched, circular, and ball-shaped mitochondria have been reported. Recent research suggests that mitochondrial morphology may reflect functional status of the cell. In this study, we investigated the density and ratio of the each morphological categories of mitochondria in a few normal cultured cells; astrocyte, HeLa and COS7 cells, of which metabolic activities are different, with high voltage electron microscopy. The absolute number and relative number per unit area of mitochondria was largest in astrocyte. But, the proportion of different mitochondrial shape was similar among cells. These results shows the numerical profiles but not morphological profiles of mitochondria are related to the metabolic activity of each cell line.
\end{abstract}

Key Words: Mitochondria, Astrocyte, HeLa cell, COS7 cell, High voltage electron microscopy

\section{INTRODUCTION}

Mitochondrion plays highly important roles in the energy supply. In addition, mitochondria regulate various cellular functions; steroidogenesis, apoptosis, autophagy, calcium homeostasis, development, and cell metabolism (Cerveny et al., 2007; Detmer \& Chan, 2007; Twig et al., 2008; Friederich et al., 2009; Soubannier \& McBride, 2009). Various mitochondrial functions are reflected in their structure. Mitochondria are thread-like structure under the light microscopic observation. Double membranes of mitochondrion were reported using electron microscopy (Palade, 1953). Studies of mitochondrial morphology studies using high voltage electron microscopy (HVEM) were proposed by Goldstein et al (1984). Recently, mitochondrial shapes were analyzed using HVEM. Mitochondria fall into four categories based on the morphology in the HeLa and COS7 cell lines (Kim et al., 2012). The HeLa and COS7 cells are originated from epithelial cell and have a relatively low metabolic activity.

Astrocyte is flat in culture, but complicated in morphology and high in metabolic activity in vivo. Astrocyte plays important roles in neuronal regulation such as neuronal death, degeneration, and synaptic connection (Juurlink et al., 1992; Chen \& Swanson, 2003; Eroglu \& Barres, 2010). Neurons receive any amount of energy from astrocyte and use for neuronal metabolism. Moreover, astrocyte is able to protect neurons from traumatic damage or ischemia injury (Belanger \& Magistretti, 2009; Tsai et al., 2012). In most cases, the energy metabolism is related to mitochondria in the astrocyte (Kahraman et al., 2011).

In this study, we compared mitochondrial morphology in cultured astrocyte, HeLa and COS7 cells with different metabolic activities.

(a) This is an open-access article distributed under the terms of the Creative Commons Attribution Non-Commercial License (http://creativecommons.org/licenses/by-nc/3.0) which permits unrestricted noncommercial use, distribution, and reproduction in any medium, provided the original work is properly cited.

Copyrights @ 2013 by Korean Society of Microscopy 


\section{MATERIALS AND METHODS}

\section{Whole Mount Preparation}

The sample was prepared according to the previous study for analyzing of mitochondrial morphology (Kim et al., 2012). The plastic coverslips ( $\Phi 13 \mathrm{~mm}$, Thermanox Plastic Coverslips; NUNC, Rochester, NY, USA) were punched to make $4 \sim 5$ holes $3 \mathrm{~mm}$ in diameter and coated with thick $3 \%$ formvar (\#15800; EMS, Washington, PA, USA) membrane. Formvar-coated coverslips were coated with carbon in an evaporator. The coverslips were sterilized under ultraviolet lamp for 20 minutes and used for cell culture.

Primary astrocytes were obtained from postnatal 0 to 1 day Sprague-Dawley rat pubs, cerebral cortexes according to the previous report (de Vellis \& Cole, 2012). The cerebral cortex were isolated and washed with phosphate buffered saline ( $\mathrm{pH}$ 7.6). The washed cortex was chemical dissociated in dissection media (55.5 mM D-(+)-glucose, $20.4 \mathrm{mM}$ sucrose, $4.2 \mathrm{mM}$ sodium bicarbonate in Hank's balanced salt solution) including 1\% trypsin-EDTA. After filtering through $40 \mu \mathrm{m}$ pore nylon mesh, isolated cells were seeded on culture dish in plating media (10\% fatal bovine serum, $10 \%$ horse serum, $100 \mu \mathrm{M}$ non-essential amino acid, $2 \mathrm{mM}$ glutamine, $1 \%$ antibiotics in Dulbecco's modified Eagle's medium [DMEM]). One day after in the incubator $\left(37.5^{\circ} \mathrm{C}, 5 \% \mathrm{CO}_{2}\right)$, cell media were changed with the growth media ( $5 \%$ fatal bovine serum, $5 \%$ horse serum, $100 \mu \mathrm{M}$ non-essential amino acid, $2 \mathrm{mM}$ glutamine, 1\% antibiotics in DMEM) and maintained for 2 weeks. The matured astrocytes were seeded onto the prepared coverslips placed in 12-well cell culture dish at the density of $3 \times 10^{3}$ cells per well. HeLa cells and COS7 cells were seeded on prepared coverslips at the same density.

\section{High Voltage Electron Microscopy}

When the cultured cells fill up 50 70\% at the cover slip surface, cells were rinsed with $0.1 \mathrm{M}$ sodium cacodylate buffer (CB; pH 7.4) and processed for fixation. After washing, prefixed with $2.5 \%$ glutaraldehyde in $0.1 \mathrm{M} \mathrm{CB}$ for 30 minutes
A

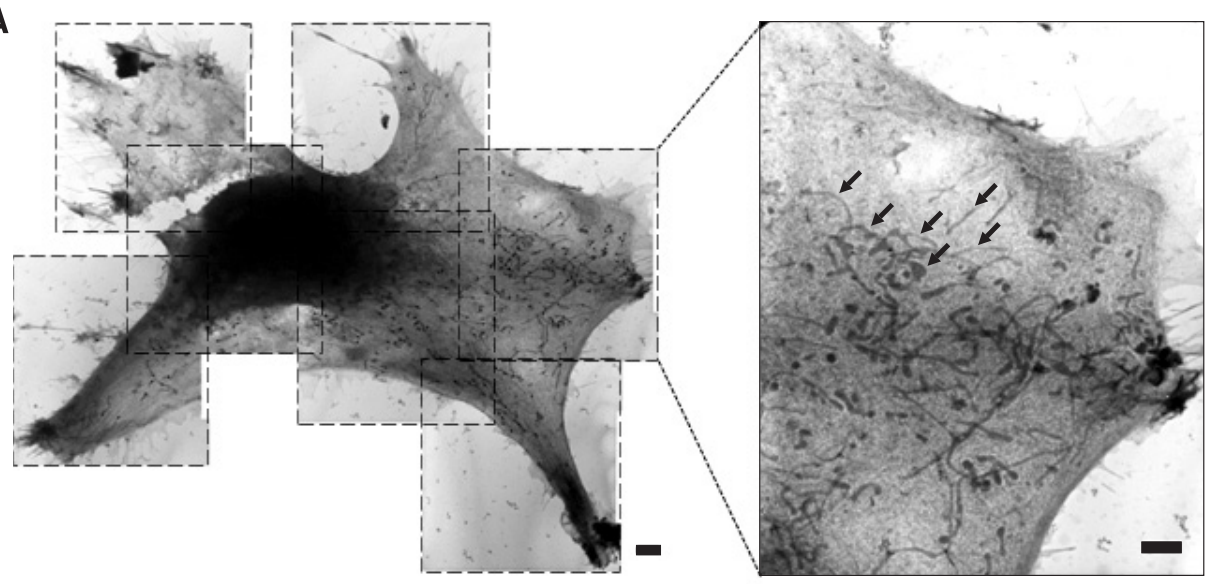

B

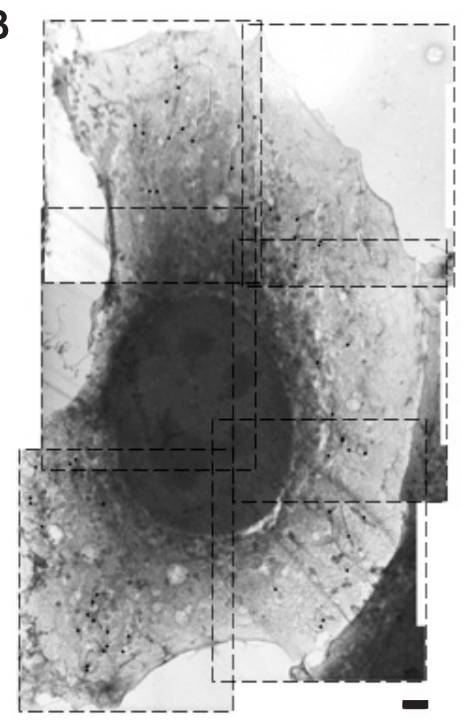

C

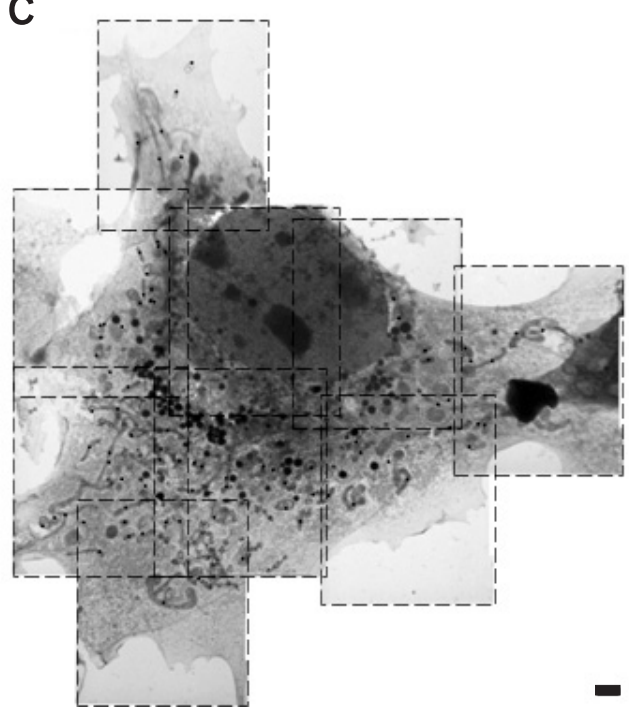

Fig. 1. Montages of the different cells using high voltage electron micrographs of the cultured cells: astrocyte (A), HeLa cell (B), and COS7 cell (C). Each montage was made of 6 to 10 images of $\times 3,000 \sim \times 4,000$ micrographs. Enlarged portion of the montage shows thread-like mitochondria (A, arrows). Scale bars $=1 \mu \mathrm{m}$. 
at room temperature and post-fixed with $1 \%$ osmium tetroxide in $0.2 \mathrm{M} \mathrm{CB}$ for 30 minutes at room temperature. Samples were washed with $30 \%$ ethanol after post-fixation for 30 minutes. Fixed coverslips were en bloc stained with $0.1 \%$ uranly acetate in $30 \%$ ethanol for 30 minutes at room temperature. The coverslips were then dehydrated with increasing series of ethanol and then freeze-dried. Mesh cement-coated single slot grid were used for observation. The grids were laid up the hole on the coverslip, lifting the formvar membrane including cells. Specimens were observed under HVEM (H-1250M; Hitachi, Tokyo, Japan) at 1 MV of accelerating voltage. Magnified electron microscopic images to $\times 3,000 \sim \times 4,000$ were stitched using Adobe Photoshop 7.0 software (Adobe Systems, San Jose, CA, USA). Stitched montage images were analyzed using Scion Image software (Scion Corporation, Frederick, MD, USA). Parameters of mitochondrion contents for analysis were same as in the previous report (Kim et al., 2012).

\section{Statistics}

For mitochondria contents, one-way ANOVA and two-way ANOVA were used to compare astrocyte and epithelial cell. Post test followed one-way ANOVA were Turkey's multiple comparison test. All analyses were done using the GraphPad Prism (GraphPad Software Inc., San Diego, CA, USA).

\section{RESULTS}

Mitochondria information from astrocyte, HeLa cell and COS7 cell were analyzed using whole mount cell image made of whole cell montage (Fig. 1). Each cell montage was made from high magnificent $8 \sim 10$ single frame stitch under software. The mitochondrion was appeared thread-like structure in the peripheral zone of the cell (Fig. 1A, arrows).

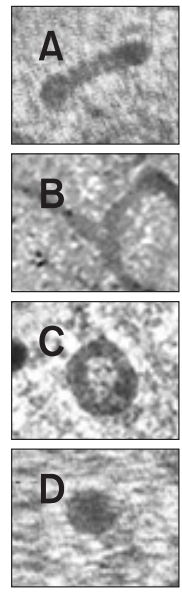

\section{E}

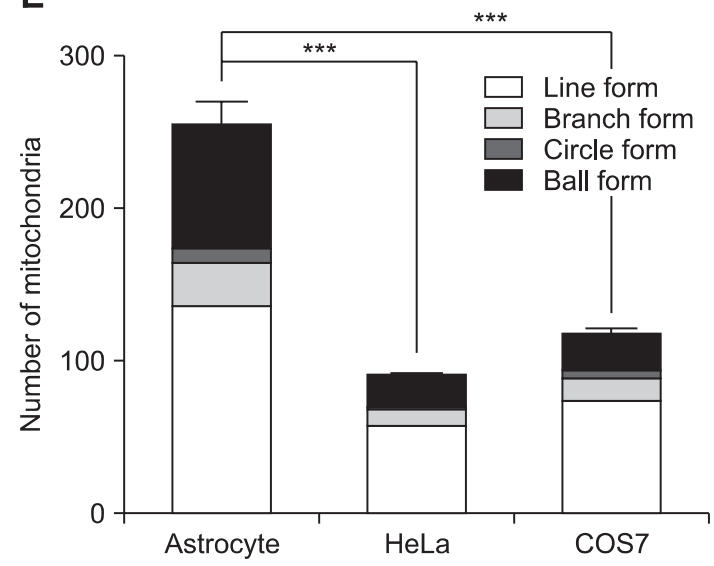

$\mathbf{F}$

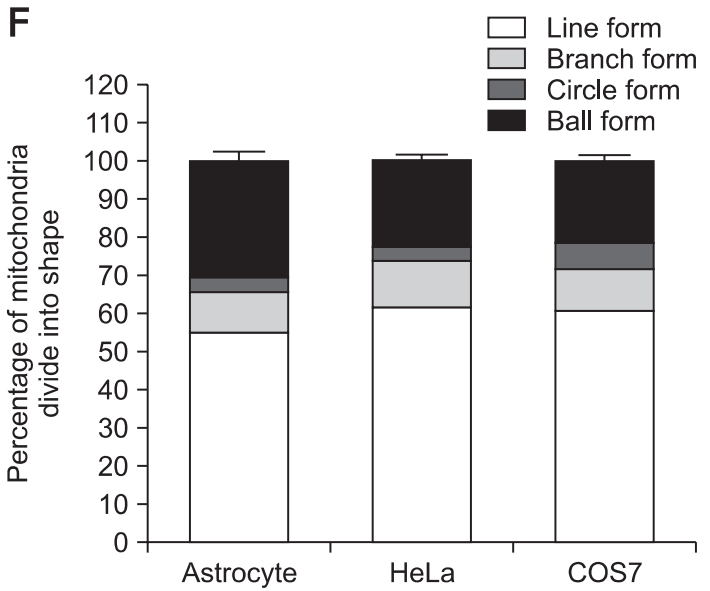

Fig. 2. Electron micrographs of four types mitochondria (A: line form, B: branch form, C: circle form, D: ball form). There was significant difference in the total number of mitochondria between glial cells (astrocyte) and epithelial cells (HeLa cell, COS7 cell; E). ***p<0.0001. However, the ratio of each types were similar (F).

A

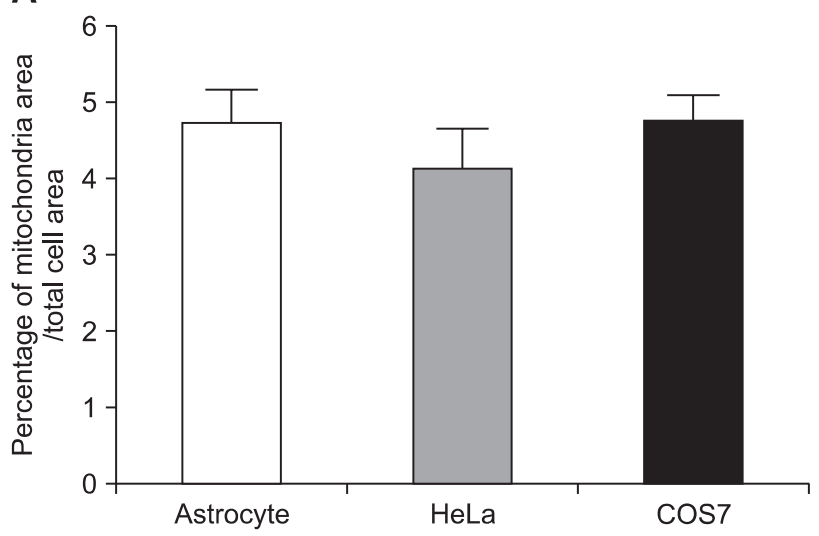

B

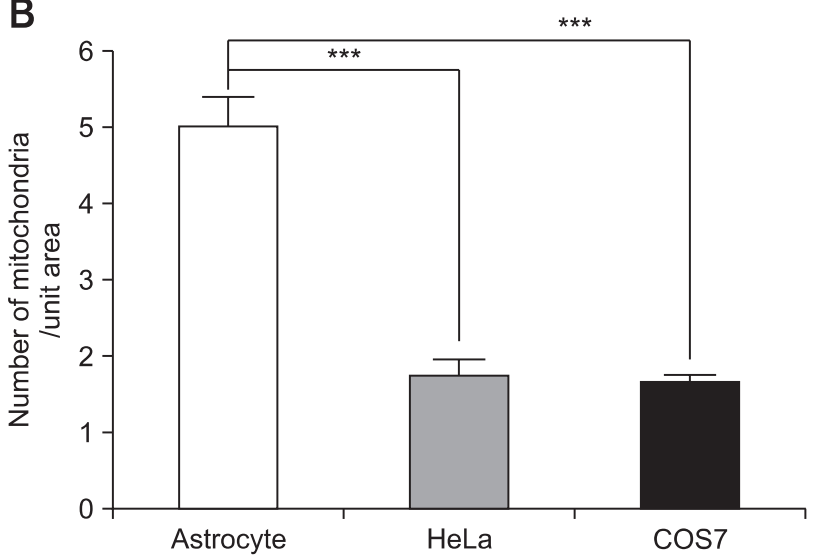

Fig. 3. There were no significant difference of mitochondrial area in total cell area between glial cell and epithelial cell (A). However, number of mitochondria per unit area $\left(10 \mu \mathrm{m}^{2}\right)$ were significantly higher in glial cell than in epithelial cell (B). ${ }^{* * *} \mathrm{p}<0.001$. 
However, mitochondria near the nucleus zone was hampered because of the cell thickness. This problem could be overcome by serial sectioning transmission electron microscopy with tomography (Takaoka et al., 2008). We choose 15 cells per each cell type for mitochondrial contents analyzing. Mitochondria were divided into four categories according to shape: line form, branch form, circle form, and ball form (Fig. 2A-D). Previous study showed that mitochondrial contents of HeLa cell and COS7 cell were similar (Kim et al., 2012). However, there were big difference in mitochondria contents between astrocyte (174.6 \pm 19.1 per cell) and epithelial cells $(79.7 \pm 6.4$ per cell in HeLa, 97.8 \pm 8.6 per cell in COS7; Fig. 2E). Total number of mitochondria was higher in astrocyte than epithelial cell significantly. In contrast, proportion of differently-shaped mitochondria was similar among the observed cells (Fig. $2 \mathrm{~F}$ ). The mitochondria contents based on the cellular area of each cells and computed ratio of mitochondria contents (Fig. $3 \mathrm{~A}$ ) showed no significant difference between astrocyte and epithelial cells. However, number of mitochondria per unit cell area $\left(1 \mu \mathrm{m}^{2}\right)$ was significantly higher in astrocytes than in epithelial cells (Fig. 3B).

\section{DISCUSSION}

The mitochondria produces 95\% of energy used in the cell and is a hot spot of researches covering anthropology, biochemistry, biophysics, cell biology, diseases, evolution, forensics, genetics, history, and more (Scheffler, 1999).

The number of mitochondria per each cell showed 100 250 according to cell types in this study (astrocyte, 253 $\pm 31.7 ; \mathrm{HeLa}$

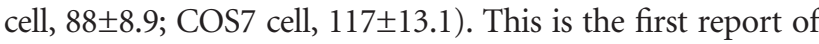
the mitochondria number of astrocyte, HeLa and COS7 cell in our best knowledge, although the mitochondria numbers of several kind of cells were reported by morphometric analysis: In case of human hepatocyte contains 800 2,000 mitochondria/cell: ovum contains 100,000 mitochondria (Scheffler, 1999). The estimation based on mitochondrial
DNA amount suggested 93 690 mitochondria/cell (Robin \& Wong, 1988).

Two electron tomograms of Langerhans islet beta cell of the murine pancreas provided detailed information on mitochondria (Noske et al., 2008). Total number of mitochondria per cell was 249 and 168, which are very close to the number of mitochondria of astrocyte obtained in this study (253 \pm 31.7 , Fig. $2 \mathrm{E})$, but the mitochondria numbers of HeLa $(88 \pm 8.9)$ and COS7 (117 \pm 13.1$)$ were lower compared to the beta cell and astrocyte.

Astrocyte is the largest glial cell type in the brain. Astrocyte has lots of functions in the brain, such as gliotransmission, neuroprotection secretion, neuropeptide secretion, homeostasis, pain, and memory (Juurlink et al., 1992; Chen \& Swanson, 2003; Eroglu \& Barres, 2010). Most of astrocyte functions are engaged in neuronal support, which means that astrocytes require high population of mitochondria for energy resource. Significantly higher number of astrocyte mitochondria might be related to their high energy demand in cell metabolism.

The analysis of mitochondrial morphology according to their shape does not showed any statistical difference among cell types in this study. This may implies that the given ratio of mitochondrial shape is maintained constantly in physiological cell conditions. Further analysis based on the pathological models would give us more insight to understand this finding. No difference of mitochondrial volume fraction among the cells in this study is interesting, but it also requires further studies to explain.

\section{SUMMARY}

We presented mitochondria contents successfully in different types of cultured cells using HVEM with whole mount technique. Total number of mitochondria per unit area was significantly higher in astrocyte. This might implies that the number and ratio of mitochondria varies depending on the function at status of the cells.

\section{REFERENCES}

Belanger $\mathrm{M}$ and Magistretti P J (2009) The role of astroglia in neuroprotection. Dialogues Clin. Neurosci. 11, 281-295.

Cerveny K L, Tamura Y, Zhang Z, Jensen R E, and Sesaki H (2007) Regulation of mitochondrial fusion and division. Trends Cell Biol. 17, 563-569.

Chen Y and Swanson R A (2003) Astrocytes and brain injury. J. Cereb. Blood Flow Metab. 23, 137-149.

de Vellis J and Cole R (2012) Preparation of mixed glial cultures from postnatal rat brain. Methods Mol. Biol. 814, 49-59.

Detmer S A and Chan D C (2007) Functions and dysfunctions of mitochondrial dynamics. Nat. Rev. Mol. Cell Biol. 8, 870-879.
Eroglu C and Barres B A (2010) Regulation of synaptic connectivity by glia. Nature 468, 223-231.

Friederich M, Hansell P, and Palm F (2009) Diabetes, oxidative stress, nitric oxide and mitochondria function. Curr. Diabetes Rev. 5, 120144.

Goldstein S, Moerman E J, and Porter K (1984) High-voltage electron microscopy of human diploid fibroblasts during ageing in vitro. Morphometric analysis of mitochondria. Exp. Cell Res. 154, 101-111.

Juurlink B H, Hertz L, and Yager J Y (1992) Astrocyte maturation and susceptibility to ischaemia or substrate deprivation. Neuroreport $\mathbf{3}$, 1135-1137. 
Kahraman S, Bambrick L L, and Fiskum G (2011) Effects of FK506 and cyclosporin a on calcium ionophore-induced mitochondrial depolarization and cytosolic calcium in astrocytes and neurons. J. Neurosci. Res. 89, 1973-1978.

Kim H W, Oh S H, Kim J W, Cho B, Park I S, Sun W, and Rhyu I J (2012) Efficient and accurate analysis of mitochondrial morphology in a whole cell with a high-voltage electron microscopy. J. Electron. Microsc. (Tokyo) 61, 127-131.

Noske A B, Costin A J, Morgan G P, and Marsh B J (2008) Expedited approaches to whole cell electron tomography and organelle markup in situ in high-pressure frozen pancreatic islets. J. Struct. Biol. 161, 298-313.

Palade G E (1953) An electron microscope study of the mitochondrial structure. J. Histochem. Cytochem. 1, 188-211.

Robin E D and Wong R (1988) Mitochondrial DNA molecules and virtual number of mitochondria per cell in mammalian cells. J. Cell Physiol. 136, 507-513.
Scheffler I E (1999) Mitochondria (Wiley-Liss, New York).

Soubannier V and McBride H M (2009) Positioning mitochondrial plasticity within cellular signaling cascades. Biochim. Biophys. Acta 1793, 154-170.

Takaoka A, Hasegawa T, Yoshida K, and Mori H (2008) Microscopic tomography with ultra-HVEM and applications. Ultramicroscopy $\mathbf{1 0 8}$, 230-238.

Tsai H H, Li H, Fuentealba L C, Molofsky A V, Taveira-Marques R, Zhuang H, Tenney A, Murnen A T, Fancy S P, Merkle F, Kessaris N, Alvarez-Buylla A, Richardson W D, and Rowitch D H (2012) Regional astrocyte allocation regulates CNS synaptogenesis and repair. Science $\mathbf{3 3 7}$, 358-362.

Twig G, Elorza A, Molina A J, Mohamed H, Wikstrom J D, Walzer G, Stiles L, Haigh S E, Katz S, Las G, Alroy J, Wu M, Py B F, Yuan J, Deeney J T, Corkey B E, and Shirihai O S (2008) Fission and selective fusion govern mitochondrial segregation and elimination by autophagy. EMBO J. 27, 433-446. 